\title{
Efektivitas Modul Hybrid Project Based Learning (H-Pjbl) Berbasis Laboratorium Untuk Meningkatkan Keterampilan Proses Sains Siswa
}

\author{
Ihsan Nurdiansah \& Yanti Sofi Makiyah \\ Program Studi Pendidikan Fisika, Universitas Siliwangi \\ *Email: ihsannurdiansyah2000@gmail.com
}

Received: 25 Juni 2021; Accepted: 16 September 2021; $\quad$ Published: 10 November 2021 DOI: http://dx.doi.org/10.29303/jpft.v7i2.2750

\begin{abstract}
This study aimed to described the effectiveness of the Laboratory-Based Hybrid Project Based Learning Module to improve students' science process skills. This study uses a quasi-experimental method with a one-group pre-test pre-test design. The research sample was selected randomly from the population of class X TKRO SMKN 1 Manonjaya students. Data analysis was seen from the results of the pre-test pre-test obtained by students, $t$-test and $N$-gain to determine the improvement of students' scientific process skills descriptively. The results of the study obtained that the results of the pre-test and post-test of students increased by $37.26 \%$, then the $t$-test analysis where t_count $>$ t_table obtained a value of 3.54> 1.76 then Ho was rejected so that there was a significant difference between the pretest and posttest scores. after using the laboratory-based Hybrid Project Based Learning module, it can improve students' science process skills (KPS). However, based on the gain value obtained, 0.3 is still categorized as "medium" because there are several shortcomings during the teaching and learning process $(K B M)$.
\end{abstract}

Keywords: Module; H-PjBL; Laboratory; Science process skills

\section{PENDAHULUAN}

Pada tahun 2021 ini kondisi dunia termasuk Indonesia sedang dilanda bencana pandemi Covid-19. Dimana pandemi ini hampir berdampak pada semua kegiatan masyarakat karena pemerintah melakukan pembatasan kegiatan, agar coronavirus ini tidak menyebar dengan cepat. Salah satu pembatasan yang dilakukan yaitu dengan kegiatan pembelajaran yang mana tadinya dilakukan di Sekolah melainkan menjadi dirumah atau di istilahkan dengan pendidikan jarak jauh (PJJ), meskipun untuk kondisi sekarang ada beberapa sekolah yang sudah menerapkan pembelajaran secara tatap muka, namun pembelajaran tersebut kurang efektif karena kekhawatiran akan munculnya cluster baru Covid-19 dan kebanyakan siswa melakukan pembelajaran secara online.

Pembelajaran fisika seringkali dirasakan sukar dipelajari dan sering menjadikan siswa mengeluh apalagi pada kondisi pembelajaran online sekarang. Hal ini sejalan dengan pendapat Suryandari \& Burhendi (2020) menyatakan bahwa, dalam pembelajaran online sebagian siswa mengaku kesulitan dalam memahmi materi pelajaran fisika yang bersifat konkret dan abstrak, tanpa siswa mempertanyakan bagaiamana konsep fisika tersebut di dapat, karena kegiatan komunikasi antara siswa dengan guru dilaksanakan tanpa tatap muka. Untuk menyampaikan pertanyaan via tulisan (chat) juga siswa sulit menjabarkan pertanyaan dibandingkan bertanya secara langsung. Kehadiran Covid-19 ini membuat siswa merasa kesulitan dan kelelahan dalam mengikuti proses pembelajaran yang dilakukan secara online (Clarissa et al. 2020)

Apalagi pada kondisi sekarang yang mana pembelajaran dilaksanakan secara online, guru hanya memberikan materi dan tugas saja tanpa melibatkan siswa untuk memperoleh pengetahuan secara langsung, sehingga siswa kesulitan dalam memahami 
materi ketika proses pembelajaran. Selain itu juga proses pembelajaran hanya bersumber dari bahan ajar yang diberikan oleh guru, dan jarang melakukan kegiatan laboratorium/prakitukum. Sehingga proses pembelajaran fisika tidak melibatkan siswa untuk mengontruksi pengetahuannya secara mandiri, dan dengan mudah melupakan materi yang telah dipelajari saat itu, membuat pembelajaran menjadi kurang bermakna. Pembelajaran seperti ini dapat menyebabkan rendahnya keterampilan proses sains siswa. Rendahnya keterampilan proses sains siswa ditandai dengan masih fokusnya pembelajaran pada hasil belajar, membuat kemampuan siswa dalam observasi, interpretasi, klasifikasi, prediksi dan hipotesa menjadi tidak berkembang (Angga, et al. 2016). Berkenaan hal tersebut salah satu cara yang baik agar siswa memperoleh pengetahuan secara langsung yaitu melalui kegiatan laboratorium atau praktikum. Pada dasarnya kegitan laboratorium merupakan bagian dari pembelajran sains. Pembelajaran sains menpunyai karakteristik yaitu: merancang dan merakit suatu instrumen percobaan, mengumpulkan alat dan bahan, mengolah data, dan menafsirkan data, menyusun laporan, serta mengkomunikasikan hasilnya baik secara lisan maupun tertulis (Putri, 2012). Menurut Wilcox \& Lewandowski, 2017) kegiatan laboratorium sangat penting dalam kurikulum fisika dan direkomendasikan untuk di implementasika langsung dalam pembelajaran fisika dan dapat meningkatkan kualitas pembelajaran sains.

Sementara itu kurangnya pemahaman konsep materi pembelajaran disebabkan oleh belum adanya kesadaran akan belajar mandiri di rumah oleh siswa (Alimin \& Effendi, 2020). Solusi dari pemasalahan itu adalah memberikan bahan ajar yang dapat dipelajari oleh siswa secara mandiri di rumah yaitu berupa modul pembelajaran. Menurut Alimin \& Effendi (2020) menyatakan bahwa modul merupakan suatu media pembelajaran yang berisi kumpulan bahan ajar kompleks yang di sajikan dalam bentuk "Self-intruction", dapat diartikan bahwa modul itu bisa dipelajari oleh siswa secara mandiri dengan bantun yang terbatas dari guru. Selain itu modul ajar adalah sarana pembelajaran dalam bentuk tertulis/cetak yang disusun secara sistematis, memuat materi pembelajaran, metode, tujuan pembelajaran berdasarkan kompentensi dasar atau indikator pencapaian kompentensi, petunjuk kegiatan belajar mandiri dan memberikan kesempatan kepada siswa untuk belajar secara mandiri (I Ketut, 2018). Modul sebagai unit materi kurikulum yang tersusun lengkap dan dapat ditambahkan dengan pencapaian tugas yang lebih besar ataupun tujuan jangka panjang yang dapat membantu guru dan siswa dalam proses pembelajaran (Zulaiha \& Kusuma, 2020)

Berdasarkan permasalahan yang sudah di bahas diatas maka perlu dibutuhkan solusi yang efektif dalam memhami konsep materi fisika dengan siswa belajar secara mandiri dan terlibat langsung dalam proses pembelajaran melalui pembuatan proyek dan percobaan laboratorium yang di integrasikan dengan penggunaan teknologi informasi dan komunikasi dalam kegiatan pembelajaran yaitu melalui modul Hybrid Project Based Learning berbasis laboratorium yang dapat meningkatkan keterampilan proses sains siswa. Hybrid learning adalah memadukan antara kegiatan pembelajaran tatap muka dengan pembelajaran online berbasis teknologi komputer dan internet (Siti Nur Afidah, 2020). Sedangkan Project Based Learning merupakan model pembelajaran yang melibatkan siswa secara aktif dalam merancang tujuan pembelajaran untuk 
menghasilkan produk atau proyek yang nyata. (Oktadifani et al, 2017). Hybrid Project Based Learning merupakan kegiatan pembelajaran yang menggabungkan pembelajaran tatap muka dan pembelajaran online dengan siswa merancang langsung sebuah proyek untuk memecahkan suatu permasalahan.

Berdasarkan hasil penelitian sebelumnya mengenai model pembelajaran Hybrid Project Learning yang dilakukan Abdulkadir Rahadjianto, et al. (2019,hlm.179) Hasil penelitian menunjukkan bahwa penerapan HybridPjBL berpengaruh signifikan terhadap pencapaian hasil belajar dan keterampilan berpikir kreatif. Hasil penelitian ini menunjukkan bahwa Hybrid-PjBL merupakan alternatif pembelajaran yang sesuai dengan tuntutan abad 21. Penelitian Husamah (2015) menyatakan bahwa penggunaan Hybrid-PjBL berdampak positif terhadap perkembangan keterampilan berpikir siswa. Hasil penelitian Sih Kusumaningrum (2016) menyatakan bahwa perangkat pembelajaran biologi dengan model PjBL efektif untuk meningkatkan keterampilan proses sains dan kreativitas pada siswa kelas X SMAN 8 Yogyakarta.

Berdasarkan beberapa hasil penelitian yang sudah dijabarkan diatas bahwa modul pembelajaran dengan menggunakan model hybrid project based learning berbasis laboratorium belum ada yang meneliti, sehingga menjadi alternatif bahan ajar yang sesuai dengan kondisi sekarang ini, karena siswa dapat belajar secara mandiri berdasarkan petunjuk dan instruksi yang disajikan secara sistematis dengan siswa diajak langsung untuk membuat suatu proyek terkait praktikum sederhana dengan melakukan kegiatannya secara mandiri, kreatif, dan bereksplorasi, dengan siswa mambuat langsung alat praktikumnya secara mandiri dengan alat dan bahan yang mudah ditemukan dalam kehidupan sehari-hari. Sehingga siswa menemukan suatu konsep fisika, dengan proses mengamati, mengelompokkan, menafsirkan, memprediksi, mengajukan pertanyaan, merumuskan hipotesis, merencanakan percobaan sederhana, menggunakan alat dan bahan, menerapkan konsep, mengkomunikasikan dan melaksanakan percobaan secara mandiri, dan dapat meningkatkan keterampilan proses sains siswa dalam pembelajaran fisika. Dalam konteks sains fisika keterampilan proses sains merupakan keterampilan untuk memperoleh produk fisika melalui prosedur ilmiah (Hardiayanto, 2015)

Penelitian ini dilaksanakan di SMKN 1 MANONJAYA kelas X TKRO dan materi yang dipilih untuk penelitian ini adalah fluida dinamis yang didasarkan atas beberapa pertimbangan, yaitu (1) sesuai dengan arahan kompetensi inti dan kompetensi dasar yang tertera dalam Permendikbud Nomor 36 tahun 2018 tentang KI dan KD dimana siswa diarahkan untuk membuat dan menguji proyek sederhana yang menerapkan frinsip fluida dinamik. (2) proyek atau alat peraga praktikum yang dibuat yaitu pipa venturi yang merupakan alat untuk mengukur kecepatan aliaran fluida.

\section{METODE PENELITIAN}

Penelitian ini menggunakan rancangan eksperimen semu (quasi experimen) yaitu perlakuan diberikan pada variabel bebas yang mana variabel bebas pada penelitian ini adalah penggunaan modul hybrid project based learning berbasis laboratorium yang sudah di validasi oleh dosen melalui lembar validasi, kemudian menentukan pengaruhnya pada variabel terikat yaitu peningkatan keterampilan proses sains siswa.

Penelitian ini menggunakan rancangan one-group pre-test pre-test yaitu satu 
kelompok saja (Sugiyono, 2013). Dalam penelitian ini hanya terdapat satu kelas eksperimen tanpa ada kelas kontrol. Populasi yang akan diteliti adalah kelas $\mathrm{X}$ TKRO SMKN 1 Manonjaya. Penentuan sampel dalam penelitian ini menggunakan teknik Simple Random Sampling (Sugiyono, 2013).

Teknik pengumpulan data menggunakan tes berbentuk pilihan ganda sebanyak 10 soal yang memuat 10 indikator keterampilan proses sains (KPS) dengan tes pengujian soal menggunakan uji validitas, realibitas, tingkat kesukaran, dan daya pembeda. Uji prasyarat analisis data menggunakan uji normalitas data yang selanjutnya dilakukan uji-t dan uji $\mathrm{N}$-gain untuk mengetahui efektivitas modul hybrid project-based learning berbasis laboratorium untuk terhadap peningkatan keterampilan proses sains siswa. Adapun untuk rumus uji $\mathrm{N}$-gain ialah sebagai berikut (Hake, 1999):

$$
<g>=\frac{S_{\text {Posttest }}-S_{\text {Pretest }}}{S_{\text {maxideal }}-S_{\text {Pretest }}}
$$

Keterangan

$<g>=$ Peningkatan keterampilan proses sains siswa

$\begin{array}{ll}S_{\text {Pretest }} & =\text { Skor pretet } \\ S_{\text {Posttest }} & =\text { Skor posttest } \\ S_{\text {maxideal }} & =\text { Skor maksimun ideal }\end{array}$

Kriteria $\mathrm{N}$-gain hasil peningkatan keterampilan proses sains siswa seperti yang ditunjukan pada tabel berikut:

Tabel 1. Kriteria n-gain

\begin{tabular}{cc}
\hline Nilai gain & Kriteria \\
\hline$\geq 0,7$ & Tinggi \\
$0,3<$ gain $<0,7$ & Sedang \\
$\leq 0,3$ & Rendah \\
\hline
\end{tabular}

\section{HASIL DAN PEMBAHASAN}

Keefektivan Modul Hybrid Project Based Learning berbasis laboratorium ditinjau dari peningkatan keterampilan proses sains siswa melalui hasil dari pretestdan post-testyang kemudian ditunjukan melalui uji $\mathrm{t}$ dan skor n-gain untuk melihat perbedaan hasil yang siginifikan antara skor pre-test dan skor post-test yang diperoleh siswa.

Berdasarkan Tabel 2. rata-rata hasil pre-test siswa yaitu 21,33 dan rata-rata hasil post-test siswa yaitu 34,00 maka berdasarkan hasil tersebut menunjukan kategori kurang baik. Meskipun dikategorikan kurang baik tetapi rata-rata hasil pre-testdan post-test siswa mengalami peningkatan sebsesar 37,26\%. Hal ini membuktikan penggunaan Modul Hybrid Project Based Learning berbasis laboratorium dapat meningkatkan keterampilan proses sains siswa.

Tabel 2. Rerata nilai keterampilan proses sains siswa pada kelas eksperimen

\begin{tabular}{ccccc}
\hline Kelas & $\begin{array}{c}\text { pre- } \\
\text { test }\end{array}$ & $\begin{array}{c}\text { post } \\
\text {-test }\end{array}$ & $\begin{array}{c}\text { Katego } \\
\text { ri }\end{array}$ & $\begin{array}{c}\text { Pening } \\
\text { katan }\end{array}$ \\
\hline $\begin{array}{c}\text { Eksperi } \\
\text { men }\end{array}$ & 21,33 & $\begin{array}{c}34,0 \\
0\end{array}$ & $\begin{array}{c}\text { Kurang } \\
\text { baik }\end{array}$ & $37,26 \%$ \\
\hline
\end{tabular}

Melalui hasil analisis data uji t dua sampel yang saling berhubungan dengan menggunakan statistik untuk sampel kecil diperoleh hasil seperti yang disajikan pada Tabel 3. Berdasarkan hasil pengujian hipotesis pada tabel, dapat dilihat bahwa korelasi antara skor pre-test dan post-test dikategorikan tinggi sehingga terdapat korelasi positif yang siginifikan antara hasil dari pre-testdan post-testyang diperoleh siswa. Selanjutnya berdasarkan hasil analisis menggunakan uji-t menunjukan bahwa $t_{\text {hitung }}>t_{\text {tabel }}$ yaitu $3,54>1,76$. Hal ini maka hipotesis nol ditolak sehingga terdapat perbedaan yang signifikan antara skor pretest dan posttest setelah menggunakan modul hybrid project-based learning berbasis laboratorium untuk meningkatkan keterampilan proses sains (KPS) siswa. 
Tabel 3. Hasil Uji-t

\begin{tabular}{lcccc}
\hline $\begin{array}{c}\text { Kelom } \\
\text { pok }\end{array}$ & $\begin{array}{c}\text { Kore } \\
\text { lasi }\end{array}$ & $\mathrm{dk}$ & $t_{\text {hitung }}$ & $t_{\text {tabel }}$ \\
\hline $\begin{array}{l}\text { Pre-test } \\
\text { dan }\end{array}$ & 0,60 & 14 & 3,54 & 1,76 \\
$\begin{array}{l}\text { Post-test } \\
\text { kelas }\end{array}$ & & & & \\
eksperim & & & & \\
en & & & & \\
& & & & \\
\hline
\end{tabular}

Selain itu peningkatan keterampilan proses sains (KPS) siswa dilihat berdasarkan nilai $\mathrm{N}$-gain, dimana nilai $\mathrm{N}$-gain yang didapat sebesar 0,3 dengan kategori "Sedang". Hal ini dikarenakan ada beberapa kekurangan dalam proses kegiatan belajar mengajar, baik dari segi waktu maupun proses pelaksanaanya, adanya kemungkinan pennggunaan aspek KPS yang hanya sebatas di soal saja tetap tidak dijadikan sebagai pendekatan dalam proses pembelajaran. Penilaian KPS hanya dilihat dari nilai pretest dan post-test saja, tidak dilihat dari hasil observasi keterampilan proses sains secara afektif dan psikomotorik karena kondisi sekarang yang kebanyakan siswa belajar dilaksanakan secara online.

Berdasarkan hasil penelitian yang telah dilakukan keterampilan proses sains siswa masih dikategorikan "sedang" seperti yang ditunjukan oleh nilai N-gain karena terdapat beberapa kekurang dalam proses KBM. Namun secara keseluruahn nilai pretest dan post-test serta analisis uji-t menunjukan KPS siswa meningkat setelah diberikan Modul Hybrid Project Based Learning berbasis laboratorium hal ini dilihat dari nilai pre-test dan post-test yang diperoleh siswa. Penggunaan Modul Hybrid Project Based Learning berbasis laboratorium ini efektif dapat meningkatkan keterampilan proses sains (KPS) siswa. Melalui kegiatan laboratorium dirancang dan diarahkan siswa untuk terlibat langsung mengontruksi pengetahuan dan keterampilan sains melalui proses sains.

Hal tersebut sesuai dengan pendapat Yanti (2015) bahwa pembelajaran berbasis laboratorium jug dapat melibatkan siswa dalam memperoleh pengalaman belajar sehingga dapat meningkatkan keterampilan proses sains (KPS) siswa dan mempermudah siswa dalam memahami konsep fisika. Hasil penelitian Utari (2017) bahwa keterampilan proses sainssiswa selama mengikuti pembelajaranfisika menggunakan model project based learning termasuk dalam kategori sangat baik. Hasil penelitian Abidin et al. (2020) menjelaskan bahwa pembelajaran berbasis proyek yang dilakasanakan secara online, siswa dapat memiliki pembelajaran yang bermakna, sehingga pengetahuan serta ilmu yang dimiliki dapat menjadikaan manfaat sebagai bekal dalam memecahkan masalah. Hasil penelitian Suranti, et al. (2017) bahwa terdapat pengaruh yang siginifikan terkait model project-based learning dengan bantuan media virtual terhadap penguasaan konsep fisika.

\section{PENUTUP}

Berdasarkan hasil analisis data dan pembahasan bahwa modul hybrid projectbased learning berbasis laboratorium mampu meingkatkan keterampilan proses sains siswa. Hal ini dapat dilihat dari hasil pre-test dan post-test yang diperoleh siswa dengan peningkatan sebesar $37,26 \%$, serta analisis uji $\mathrm{t}$ dimana $t_{\text {hitung }}>t_{\text {tabel }}$ yaitu 3,54 > 1,76 maka $\mathrm{H}_{\mathrm{o}}$ ditolak sehingga terdapat perbedaan yang signifikan antara skor pretestdan posttest setelah menggunakan modul hybrid project-based learning berbasis laboratorium untuk meningkatkan keterampilan proses sains (KPS) siswa. Namun berdasarkan nilai gain yang diperoleh sebesar 0,3 masih dikategorikan "sedang" karena terdapat 
beberapa kekurangan dalam proses kegiatan belajar mengajar dimana siswa kebanyakan melakukan pembelajaran secara online

\section{REFERENSI}

Suryandari, A. W., \& Burhendi, F. C. A. (2020, October). Studi Pendahuluan Karakteristik Pembelajaran Online Fisika Selama Masa Pandemi Covid19. In Prosiding Seminar Dan Diskusi Pendidikan Dasar. 2549-580.

Putra, I. A. (2015). Orientasi Hybrid Learning Melalui Model Hybrid Learning Dengan Bantuan Multimedia di Dalam Kegiatan Pembelajaran. EDUSCOPE: Jurnal Pendidikan, Pembelajaran, dan Teknologi, 1(1), 36-42.

Arizona, K., Abidin, Z., \& Rumansyah, R. (2020). Pembelajaran Online Berbasis Proyek Salah Satu Solusi Kegiatan Belajar Mengajar di Tengah Pandemi Covid-19. Jurnal Ilmiah Profesi Pendidikan, 5(1), 64-70. http://www.jipp.unram.ac.id/index.ph $\mathrm{p} /$ jipp/article/view/111

Alimin, A., \& Effendi, H. (2020). Pengembangan Modul Pembelajaran Berbasis Daring Pada Mata Diklat Instalasi Penerangan Listrik Kelas XI Di Sekolah Menegah Kejuruan. Ranah Research: Journal of Multidisciplinary Research and Development, 2(4), 133-138.

Clarissa D,. Puspitasari I.D, \& Rubini B. (2020). Problem Based Learning Terintegrasi STEM di Era Pandemi Covid-19 untuk Meningkatkan Keterampilan Berfikir Kritis Siswa. Jurnal IPA dan Pembelajaran. 4(2). 193

204.

http://jurnal.unsyiah.ac.id/jipi.

Putri, D. H. (2012). Model kegiatan laboratorium berbasis problem solving pada pembelajaran gelombang dan optik untuk meningkatkan keterampilan proses sains mahasiswa. EXACTA, 10(2), 148-155.
Hardiyanto, H., Susilawati, S., \& Harjono, A. (2017). Pengaruh Model Pembelajaran Berbasis Masalah dan Ekspositori dengan Keterampilan Proses Sains Terhadap Hasil Belajar Fisika Siswa Kelas VIII MTsN 1 Mataram Tahun Ajaran 2014/2015. Jurnal Pendidikan Fisika dan Teknologi, 1(4), 249-256. doi:http://dx.doi.org/10.29303/ipft.v1i 4.267

Husamah, H. (2015). Thinking Skills for Environmental Sustainability Perspective of New Students of Biology Education Department Through Blended Project Based Learning Model. Jurnal Pendidikan IPA Indonesia, 4(2), 110-119. doi: 10.15294/jpii.v4i2.3878

Hake, R, R. (1999). Analyzing Changed Gain Score. Indiana University. USA.

Kusumaningrum, S., \& Djukri, D. (2016). Pengembangan perangkat pembelajaran model project based learning (PjBL) untuk meningkatkan keterampilan proses sains dan kreativitas. Jurnal Inovasi Pendidikan IPA, 2(2), 241-251.

Krisnayana, I. K. A., Putrama, I. M., \& Divayana, D. G. H. (2018). Pengembangan E-Modul Berbasis Project Based Learning (PjBL) Mata Pelajaran Visual Effect Kelas XI Multimedia Di SMK TI Bali Global Singaraja. KARMAPATI (Kumpulan Artikel Mahasiswa Pendidikan Teknik Informatika), 7(2), 104-112.

Rahardjanto, A. (2019). Hybrid-PjBL: Learning Outcomes, Creative Thinking Skills, and Learning Motivation of Preservice Teacher. International Journal of Instruction, 12(2), 179-192.

Suranti, N., Gunawan, G., \& Sahidu, H. (2017). Pengaruh Model Project Based Learning Berbantuan Media Virtual Terhadap Penguasaan Konsep Peserta didik pada Materi Alat-alat Optik. Jurnal Pendidikan Fisika dan 
Teknologi, 2(2), 73-79. doi:http://dx.doi.org/10.29303/jpft.v2i $\underline{2.292}$

Sugiyono. (2013). Metode Penelitian Kuantitatif dan Kualitatif dan R\&D. Bandung: Alfabeta.

Oktadifani, U., Lesmono, A. D., \& Subiki, S. (2017). Pengaruh model project based learning terhadap keterampilan proses sains dan hasil belajar siswa dalam pembelajaran fisika di SMA. Jurnal Pembelajaran Fisika, 5(2), 109-114. http://jurnal.unej.ac.id/index.php/JPF/ article/download/3956/3084

Wilcox, B.R., \& Lewandowski, H.J. (2017). Develoving Skills Versus Reinforcing Concepts in Physics Labs: Insight from A Survey Of Student Beliefs About Experimental Physics. Physical Review Physics Education Research. 13(1). 010108-1-9.

Zulaiha, F., \& Kusuma, D. (2020). Pengembangan Modul Berbasis STEM untuk Siswa SMP. Jurnal Pendidikan Fisika dan Teknologi, 6(2), 246-255. doi:http://dx.doi.org/10.29303/jpft.v6i 2.2182 